\title{
Research on Construction Optimization of Three-Connected-Arch Hydraulic Underground Cavities Considering Creep Property
}

\author{
Bao-yun Zhao, ${ }^{1,2}$ Nian-chun $\mathrm{Xu}^{2} \mathrm{Zi}^{2}$-yun $\mathrm{Li}^{2}$, and Tong-qing $\mathrm{Wu}^{2,3}$ \\ ${ }^{1}$ Chongqing Key Laboratory of Geomechanics \& Geoenvironmental Protection, Department of Civil Engineering, \\ Logistical Engineering University, Chongqing 401311, China \\ ${ }^{2}$ Department of Civil Engineering and Architecture, Chongqing University of Science \& Technology, Chongqing 401331, China \\ ${ }^{3}$ Key Laboratory of Hydraulic \& Waterway Engineering of the Ministry of Education, Chongqing Jiaotong University, \\ Chongqing 400074, China
}

Correspondence should be addressed to Bao-yun Zhao; baoyun666@163.com and Nian-chun Xu; 351601872@qq.com

Received 8 June 2014; Accepted 21 June 2014; Published 6 August 2014

Academic Editor: Kim M. Liew

Copyright (C) 2014 Bao-yun Zhao et al. This is an open access article distributed under the Creative Commons Attribution License, which permits unrestricted use, distribution, and reproduction in any medium, provided the original work is properly cited.

In order to prevent the creep of surrounding rock in long-term construction, with consideration of different construction methods and other factors during the construction of large-scale underground cavity, three different construction schemes are designed for specific projects and a nonlinear viscoelastic-plastic creep model which can describe rock accelerated creeping is introduced and applied to construction optimization calculation of the large-scale three-connected-arch hydraulic underground cavity through secondary development of FLAC ${ }^{3 \mathrm{D}}$. The results show that the adoption of middle cavity construction method, the second construction method, enables the maximum vault displacement of $16.04 \mathrm{~mm}$. This method results in less stress redistribution and plastic zone expansion to the cavity's surrounding rock than the other two schemes, which is the safest construction scheme. The conclusion can provide essential reference and guidance to similar engineering for construction optimization.

\section{Introduction}

Since the construction period of large-scale underground cavity engineering is long, the creep property of rock mass is relatively obvious, and many large-scale underground cavities collapse and finally break down due to deformation which is continuously developing with time. The selection of reasonable construction scheme is one of the main ways to prevent and control surrounding rock's creep of the underground cavity.

In the past years, numerous scholars at home and abroad acquired lots of achievements in underground cavity construction safety $[1,2]$ and its optimization $[3,4]$ and acquired abundant accomplishment in rock mass creep constitutive model [5], creep parametric inversion [6], engineering application [7], and so forth as well. Meanwhile, lots of mathematical softwares or numerical methods were used to solve engineering problems, such as finite element method
[8], meshless or meshfree method $[9,10]$, discrete element method [11, 12], and Fast Lagrangian Analysis of Continua (FLAC) [13]. FLAC ${ }^{3 \mathrm{D}}$ is a three-dimensional software that uses full dynamics equation and has a good secondary development interface, which can simulate and help analyze the three-dimensional structure behavior and plastic flow of soil, rock, and other materials. FLAC has become the fastest and the most influential numerical analysis software in geotechnical mechanics and engineering.

This paper takes research on a three-connected-arch front inflow pool of an underground water intake pumping station somewhere in Shenzhen; before construction of the project, the FLAC ${ }^{3 \mathrm{D}}$ software [13], with secondary development of the nonlinear creep model, is applied by adopting the method of numerical simulation to survey for a construction method appropriate for the long-span hydraulic underground cavity of this region, and the optimal safety construction method has been proposed through comparative study on numerical 
simulation response, plastic zone expansion, and so forth of surrounding rock displacement variation of three kinds of construction methods. This research result can provide reference and guidance for the similar projects.

\section{Project Profile}

The underground pump station is with floor elevation of the front inflow pool at $17.3 \mathrm{~m}$, while ground elevation of current situation at $55.0 \mathrm{~m}$, with net width of the underground pump station at $26.9 \mathrm{~m}$, net length at $23.7 \mathrm{~m}$, and net height at $15.2 \mathrm{~m}$. It consists of 3 cavities, with span of single cavity exceeding $8.1 \mathrm{~m} ; 12.61 \mathrm{~m}$ in the second half of the middle cavity is not equipped with wall support, bearing by cross walls at two sides. The horizontal layout of the pool support structure and the cross-section of the second half of the pool are shown in Figures 1 and 2.

The project is proposed to be constructed among the valleys; the valley bottom is at the ground elevation of 53.1 $56.2 \mathrm{~m}$, being relatively plain. The formation lithology of the pump room is mainly distributed with residual soil at the elevation of $55.0 \sim 49.8 \mathrm{~m}$, moderately weathered limestone at the elevation of $49.8 \sim 26.0 \mathrm{~m}$, and moderately weathered quartz sandstone at the elevation under $26.0 \mathrm{~m}$.

\section{Nonlinear Viscoelastic-Plastic Creep Constitutive Model}

The nonlinear viscoelastic-plastic creep model is a tandem compound of a nonlinear viscoelastic-plastic body (the third part in Figure 3) and a Burgers creep model [14], as shown in Figure 3. And see the FLAC ${ }^{3 \mathrm{D}}$ secondary development of the model in the document manual [15].

Wherein, when $\sigma \leq \sigma_{\infty}$ (long-term strength or yield strength), the third part does not work, and the model is transformed into Burgers creep model; the creep equation of the model is as follows:

$$
\varepsilon=\frac{\sigma_{0}}{E_{1}}+\frac{\sigma_{0}}{\eta_{1}} t+\frac{\sigma_{0}}{E_{2}}\left(1-\exp \left(-\frac{E_{2}}{\eta_{2}} t\right)\right) .
$$

When $\sigma>\sigma_{\infty}$, the creep equation of the creep model is as follows:

$$
\varepsilon=\frac{\sigma_{0}}{E_{1}}+\frac{\sigma_{0}}{\eta_{1}} t+\frac{\sigma_{0}}{E_{2}}\left(1-\exp \left(-\frac{E_{2}}{\eta_{2}} t\right)\right)+\frac{\sigma_{0}-\sigma_{\infty}}{\eta_{3}} t^{n} .
$$

Here, $\eta(n, t)=t^{n-1} / \eta_{3}$, where $\eta_{3}$ is the initial value of $\eta(n, t)$.

\section{Calculation Model and Excavation Scheme}

4.1. Numerical Model. A plane strain model is adopted for calculation; the model consists of moderately weathered quartz sandstone, moderately weathered limestone, and residual soil from the bottom up; the PBA model has 16092 units and 24675 nodes in total, and side-middle cavity method has 15884 units and 24372 nodes in total. The horizontal displacement at left and right boundaries of the whole model is restrained, the vertical displacement of the

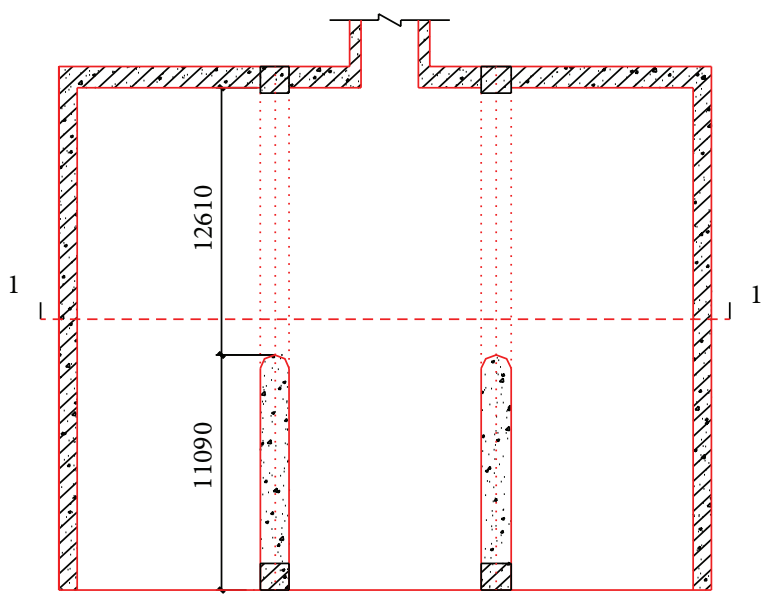

Figure 1: Plane figure of the front inflow pool.

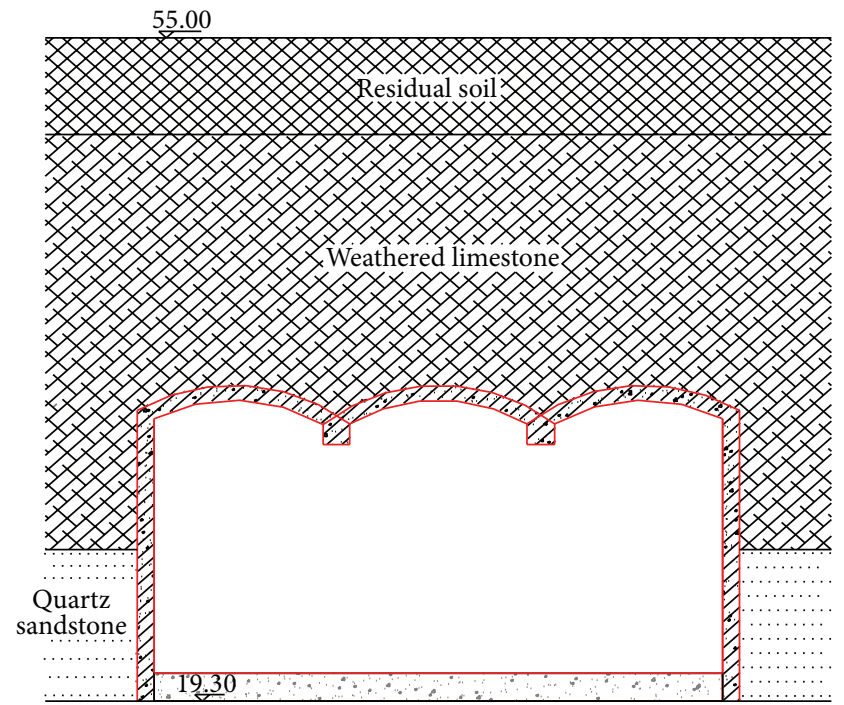

Figure 2: Cross-section (1-1) drawn of the front inflow pool.

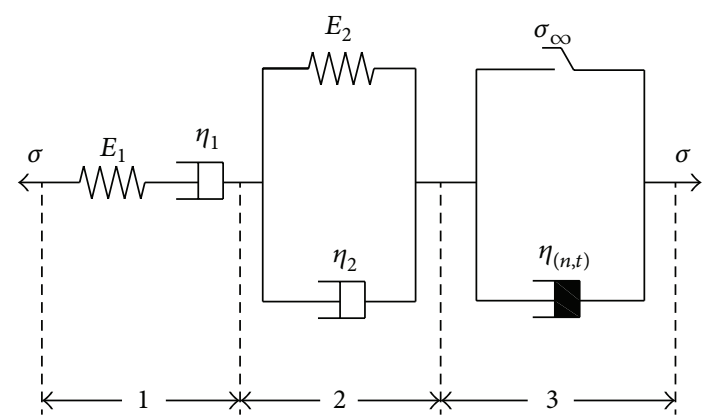

FIGURE 3: Nonlinear viscoelastic-plastic creep model.

lower boundary of the model is restrained, and the upper boundary is the free boundary. See the mesh generation of calculation model in Figure 4. 


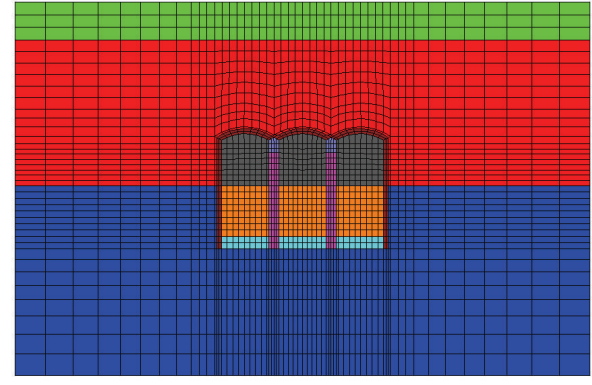

(a) The side and middle cavity methods

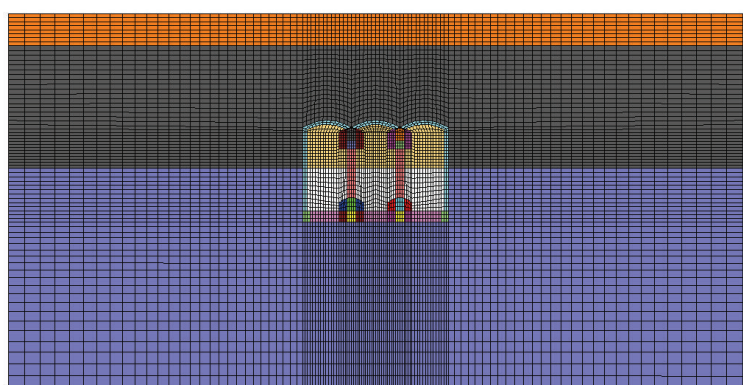

(b) PBA model

FIgURE 4: The numerical calculation model.

\subsection{The Modeling Details}

4.2.1. Parameter Selection. During the numerical analog calculation process, the elastic constitutive is adopted for initial support and secondary support. The Mohr-Coulomb constitutive is adopted for calculating the initial ground stress, and, according to the geological exploration report and indoor experiment results, the basic mechanical property and the support structure parameters of the surrounding rock at the location of the pump station can be seen in Table 1 . And the mechanical property of initial support anchor rod is shown in Table 2.

4.2.2. The Creep Calculation Details. The second-phase engineering of the three-connected-arch underground pump station mentioned in this paper is going through feasibility analysis and verification of the design stage, and site displacement deformation monitoring data is not available yet; therefore, only the moderately weathered limestone which is affected much by excavation disturbance is conducted with creep calculation (that was used the nonlinear visco-elasticplastic creep constitutive model, while other rock mass still used Mohr-Coulomb constitutive model), and the creep calculation parameter can be obtained through inversion of the site monitoring displacement data of the first-phase engineering construction; the parameter inversion is realized by adopting quasi-Newton algorithm (BFGS algorithm) Matlab programming as well, as shown in Table 3.

Three-step method was used in each cavity excavation and creep calculation age of every step is 15 days. In the process of calculation, the unbalanced force rate is set as $1 e-6$, and the time step is $1 e-4$.

4.3. Simulation Scheme of Construction Method. According to the construction experience of long-span underground cavity at home and abroad, and combining with structural features of the underground cavity mentioned in this paper, three excavation construction methods are designed here for numerical simulation optimization calculation. Excavation footage for each construction method is $2 \mathrm{~m}$, and construction among stairs is staggered for $6 \mathrm{~m} .30 \mathrm{~cm}$ of sprayed concrete and $3 \mathrm{~m}$ of anchor rod are adopted for initial support.

\subsubsection{ConstructionMethod I. Construction Procedures of Middle Cavity Method (See Figure 5)}

Step 1. Excavate the first, second, and third parts of rock mass of middle cavities, hang bar-mat reinforcement at surrounding rock in sequence, blow the anchor rod, and conduct with sprayed concrete.

Step 2. Cast ground beam 4, concrete floor 5 , stand wall 6, top beam 7 , and second lining 8 of the middle cavity.

Step 3. Excavate the ninth, tenth, and eleventh parts of the rock mass of the left cavity, dismantle the temporary support of corresponding part, and conduct the initial support such as anchor rod, and sprayed concrete.

Step 4. Cast the ground beam 12, floor 13, and left wall 14 and the second lining 15 of the left cavity.

Step 5. Excavate the right cavity with the same method as the left cavity.

\subsubsection{Construction Method II. Construction Procedures of Side Cavity Method (See Figure 6)}

Step 1. Excavate the left cavities 1, 2, and 3, and perform initial support.

Step 2. Cast the ground beam 4, stand column 5, top beam 6, floor 7 , side wall 8 , and the second lining 9 .

Step 3. Excavate the right cavities 10, 11, and 12 with the same method, and perform the initial support.

Step 4. Cast the ground beam 13, stand wall 14, top beam 15, floor 16, side wall 17, and the second lining 18 .

Step 5. Excavate the cavities 19, 20, and 21, dismantle the temporary anchor rod, and complete the lining 22 and the floor 23. 
TABLE 1: The rock mass parameters.

\begin{tabular}{|c|c|c|c|c|c|c|}
\hline Surrounding rock & $E / \mathrm{GPa}$ & $v$ & $\mathrm{C} / \mathrm{Pa}$ & $\varphi /^{\circ}$ & $\sigma_{t} / \mathrm{Pa}$ & $\rho / \mathrm{kg} \cdot \mathrm{m}^{3}$ \\
\hline Residual soil & $1.8 e-4$ & 0.3 & $1 e 4$ & 20 & $1 e 4$ & 1900 \\
\hline Weakly weathered limestone & 10 & 0.32 & $1 e 6$ & 35 & $1 e 6$ & 2400 \\
\hline Weak weathering quartz sandstone & 15 & 0.27 & $1 e 6$ & 40 & $1 e 6$ & 2500 \\
\hline Primary lining & 25 & 0.22 & & & & 2300 \\
\hline Secondary lining & 30 & 0.2 & & & & 2500 \\
\hline
\end{tabular}

TABLE 2: Mechanics parameters of cable and grout.

\begin{tabular}{lcc}
\hline The basic parameters & Unit & Values \\
\hline Cable elastic modulus & $(\mathrm{Gpa})$ & 200 \\
Cohesive force of cement slurry & $(\mathrm{kN} / \mathrm{m})$ & 800 \\
Friction coefficient of cement slurry & $\left({ }^{\circ}\right)$ & 38 \\
Stiffness of cement slurry & $\left(\mathrm{N} / \mathrm{m}^{2}\right)$ & $6.33 E 9$ \\
Outer perimeter of cement slurry & $(\mathrm{m})$ & 0.5024 \\
Cable cross-sectional area & $\left(\mathrm{m}^{2}\right)$ & $1.20 E-3$ \\
Cable tensile yield strength & $(\mathrm{MN})$ & 200 \\
\hline
\end{tabular}

TABLE 3: The nonlinear creep model parameters.

\begin{tabular}{lccccc}
\hline $\begin{array}{l}E_{1} \\
(\mathrm{GPa})\end{array}$ & $\begin{array}{c}\eta_{1} \\
(\mathrm{GPa} \cdot \mathrm{d})\end{array}$ & $\begin{array}{c}E_{2} \\
(\mathrm{GPa})\end{array}$ & $\begin{array}{c}\eta_{2} \\
(\mathrm{GPa} \cdot \mathrm{d})\end{array}$ & $\begin{array}{c}\eta_{0} \\
(\mathrm{GPa} \cdot \mathrm{d})\end{array}$ & $n$ \\
\hline 9.626 & 103.179 & 4.96 & 92.13 & 2.13 & 1 \\
\hline
\end{tabular}

\subsubsection{Construction Method III. Construction Procedures of PBA (See Figure 7)}

Step 1. Excavate pilot tunnels 1, 2, 3, and 4, hang the bar-mat reinforcement, blow the anchor rod, and spray the concrete.

Step 2. Cast the ground beams 3 and 7, dig holes and cast stand columns 5 and 8, cast the top beams 6 and 9, excavate the rock mass 10 , and cast the second lining 11 .

Step 3. Symmetrically excavate the side cavity rock masses 12,13 , and 14, dismantle the temporary support, and conduct initial support; cast side ground beam 15 , floor 16 , side wall 17 , and the second lining 18 in sequence.

Step 4. Excavate the bottom rock masses 19 and 20 of the middle cavity, dismantle the temporary support structure, and cast the floor 21 of the middle cavity.

\section{Results of Construction Optimization Calculation}

5.1. Surrounding Rock Creep Property Analysis. Figure 8 shows the excavation-completed surrounding rock displacement contour maps of three excavation methods after performing the second support; it can be seen that the maximum range of surrounding rock displacement deformation under

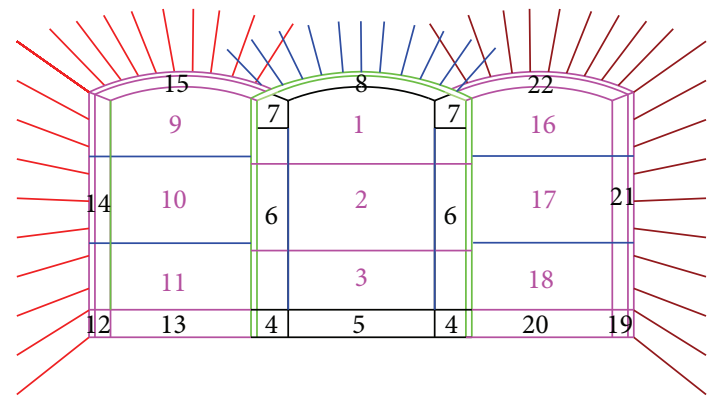

FIGURE 5: Construction steps of middle cavity method.

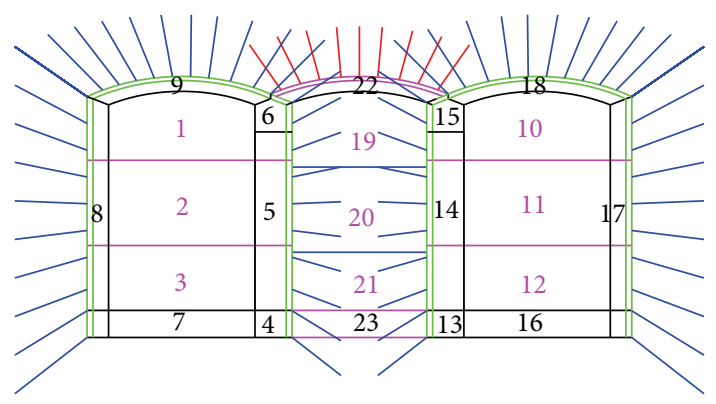

FIGURE 6: Construction steps of side cavity method.

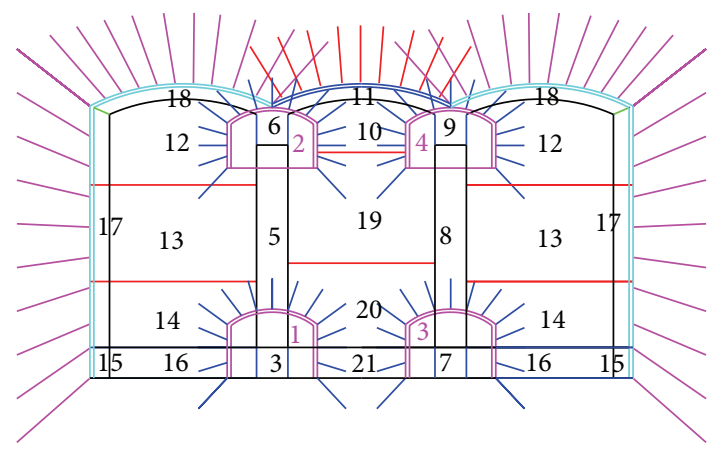

FIGURE 7: Construction method of PBA.

the three excavation methods is focused at the vault part of the three cavities.

Figure 9 shows, respectively, cavity vault part surrounding rock displacement monitoring curves of three construction methods. Each curve in the figure reflects the creep condition of the vault at each construction phase. Table 4 shows percentage statistics of vault maximum accumulative creep value and increment at each construction phase; it can 


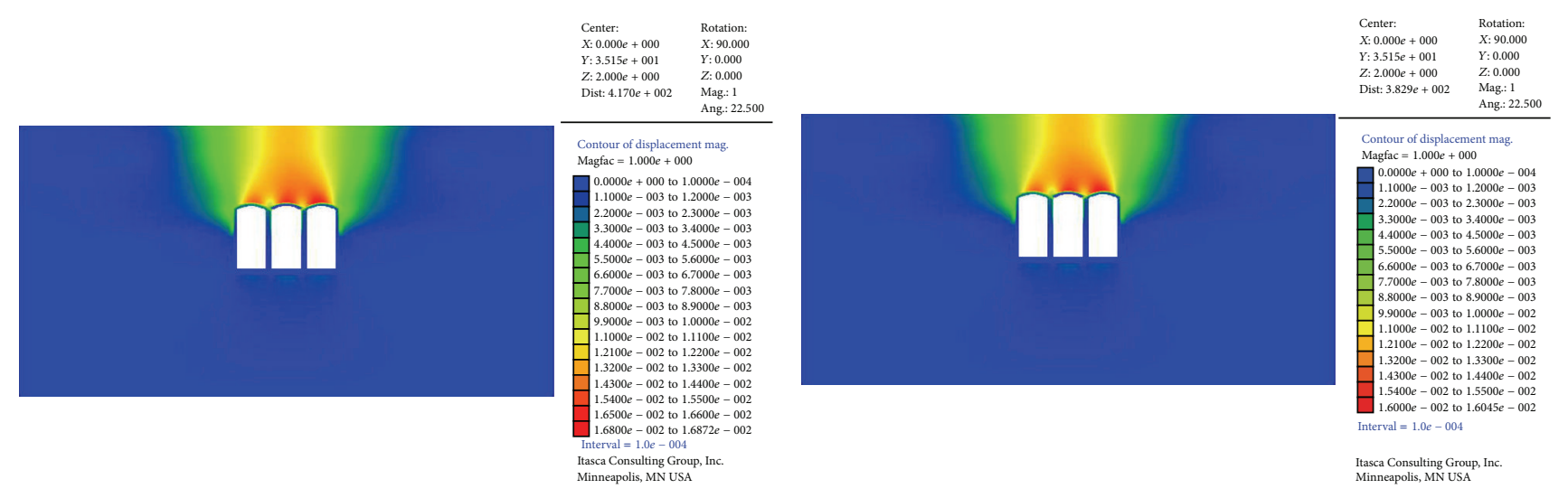

(a) Side cavity method

(b) Middle cavity method

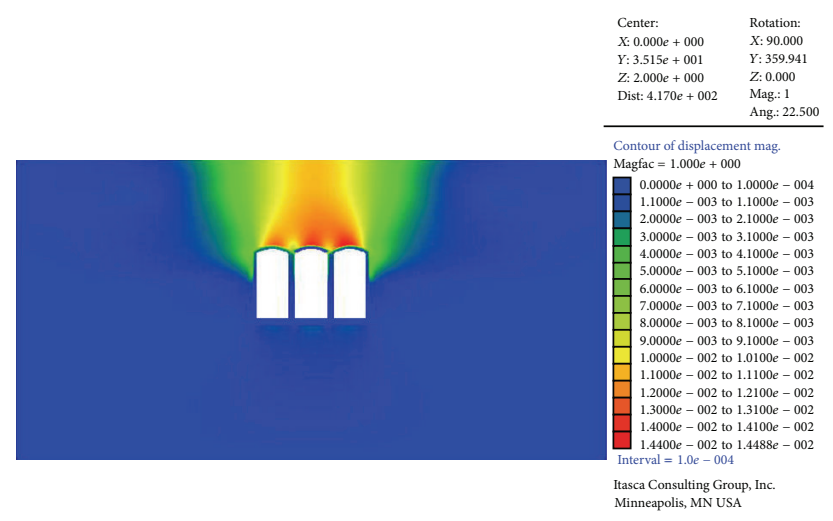

(c) PBA

FiguRE 8: Displacement contour map after excavation completed.

TABLE 4: Comparative table for maximum settlement value of phased excavation in different methods.

\begin{tabular}{lccc}
\hline \multirow{2}{*}{ Construction method } & First stage & \multicolumn{2}{c}{ Excavation complete } \\
& \multicolumn{2}{c}{ Vault maximum accumulative creep value $(\mathrm{mm})$} & 16.26 \\
Side cavity method & 13.49 & 16.04 & Increment $(\%)$ \\
Middle cavity method & 14.06 & 14.18 & 6.01 \\
PBA method & 5.09 & 3.35 \\
\hline
\end{tabular}

be seen that the first-phase creep value of the side cavity method is relatively lower, being $13.49 \mathrm{~mm}$, while the creep increment of the right cavity at second phase increases to $16.68 \%$; the vault creep value is $16.04 \mathrm{~mm}$ by adopting middle cavity method for excavation, which is $0.22 \mathrm{~mm}$ lower than that of side cavity method; for PBA construction, the excavation of pilot tunnel releases part of stress in the surrounding rock, and the beam, stand column, and the middle cavity vault second lining and other permanent supports provide well restraining effect for surrounding rock deformation in the subsequent construction, which makes the cavity maximum vault accumulative deformation being merely $14.18 \mathrm{~mm}$.

By comparing three construction methods, it can be obtained that the PBA construction is the optimal excavation construction scheme in the point of surrounding rock displacement, and the middle cavity method follows.
5.2. Stress Field Distribution Rule of Surrounding Rock. The surrounding rock maximum and minimum principle stresses variation contour map obtained after excavation completed through three excavation construction methods can be seen in Figures 10, 11, and 12. In the FLAC software, it is ruled that tension stress is positive, while pressure stress is negative; therefore, in the figure, SMin actually represents the maximum principle stress, while SMax represents the minimum principle stress. Table 5 is the numerical statistics table of maximum and minimum stresses.

All the three excavation methods enable stresses of the surrounding rock being redistributed and stress concentration appearing at the vault and the bottom part of the three cavities; the middle cavity method and the side cavity method cause the equal maximum pressure stress at $2.04 \mathrm{MPa}$, while the PBA construction causes the maximum pressure stress 


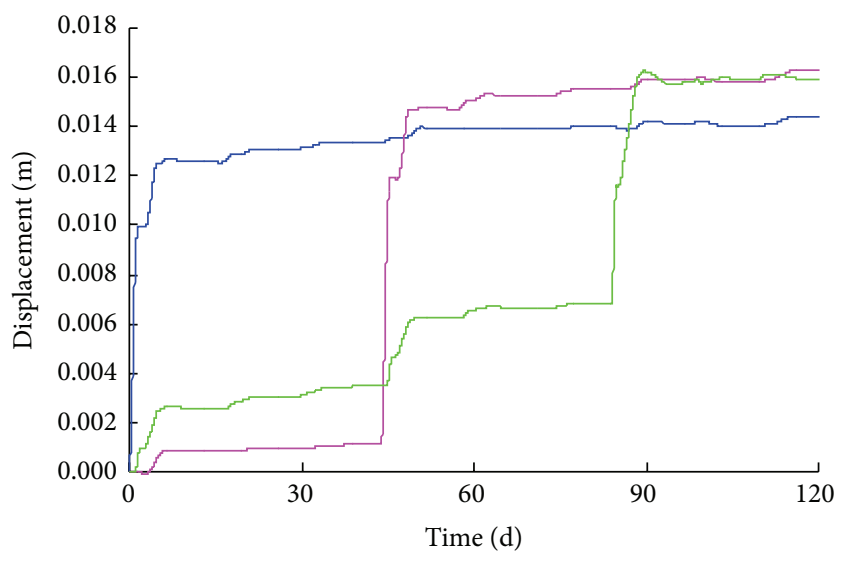

(a) Side cavity method

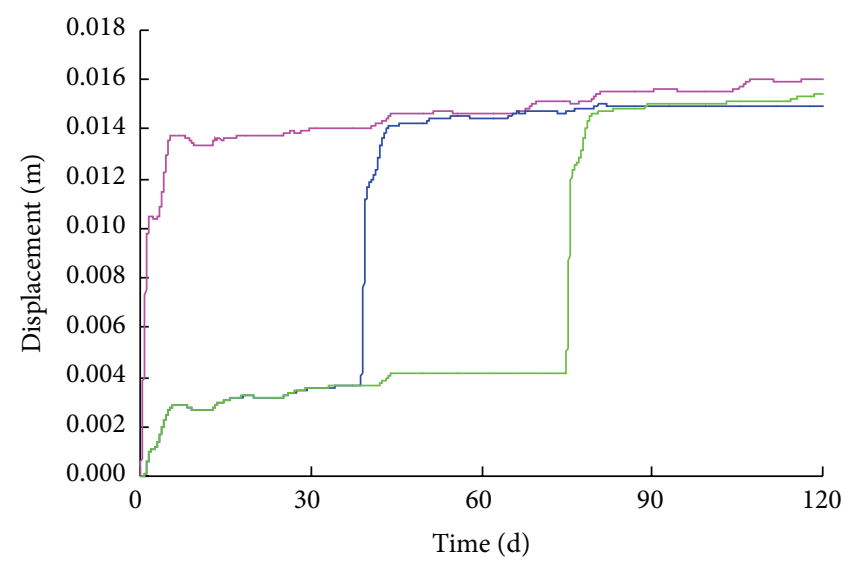

(b) Middle cavity method

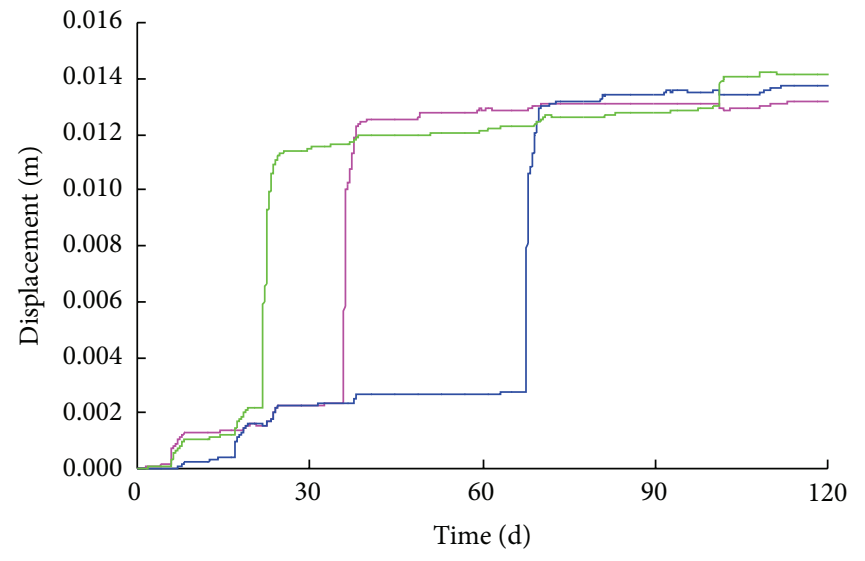

_ Peak point of middle cavity

— Peak point of left cavity

Peak point of right cavity

(c) PBA

FIGURE 9: Creep curve at vault monitoring point of excavated cavity.

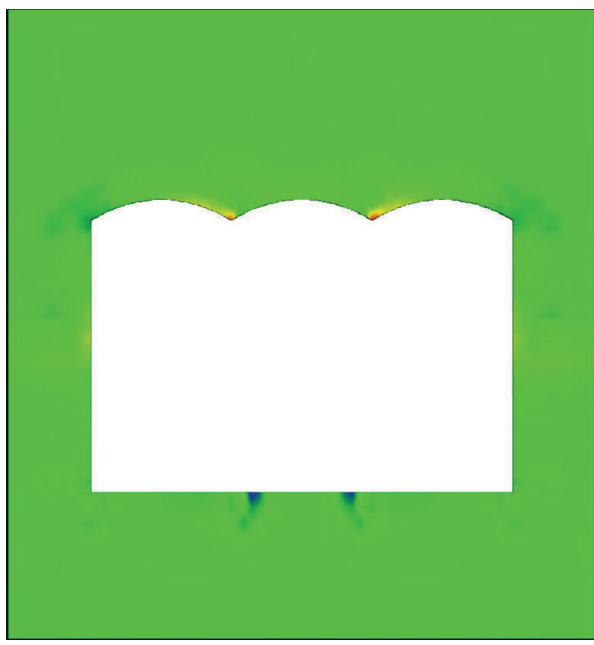

(a) Minimum principle stress

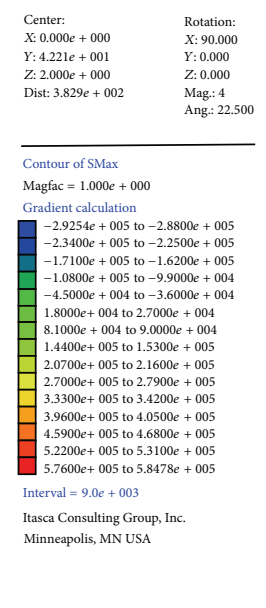

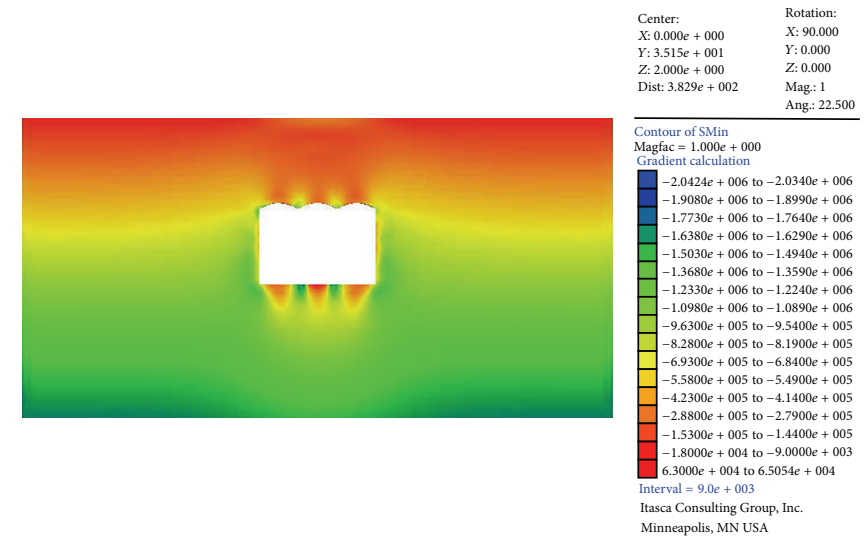

(b) Maximum principle stress

FIGURE 10: Surrounding rock principle stress contour of side cavity method. 


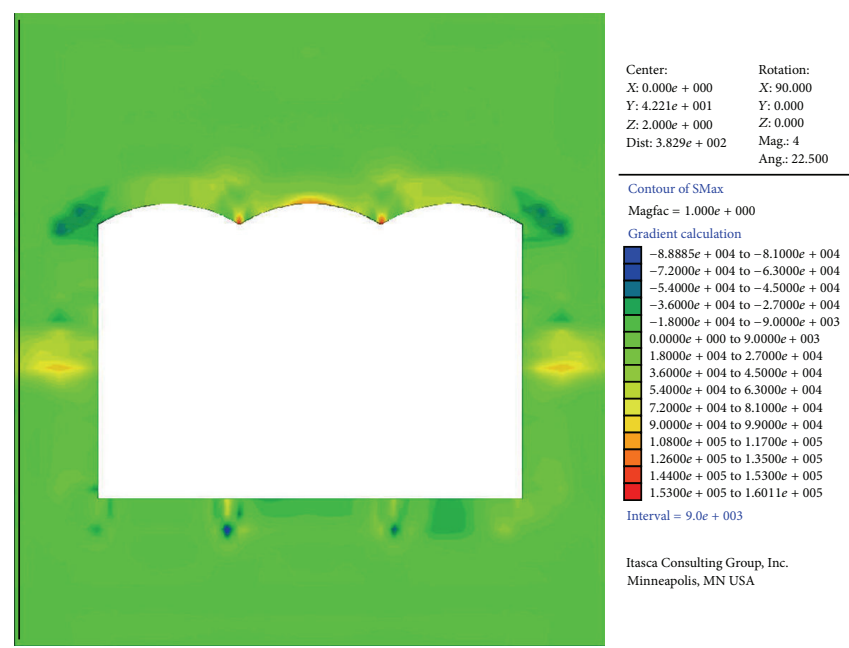

(a) Minimum principle stress

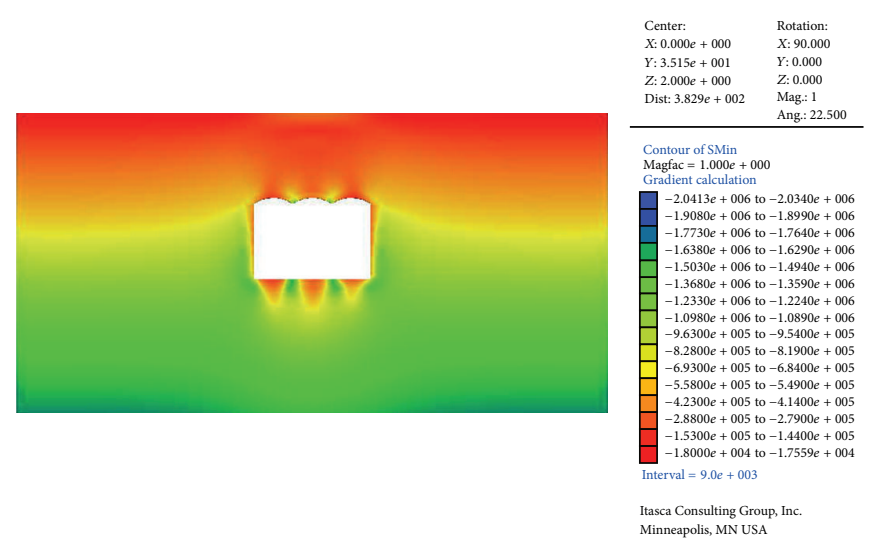

(b) Maximum principle stress

FIGURE 11: Surrounding rock principle stress contour map of middle cavity method.

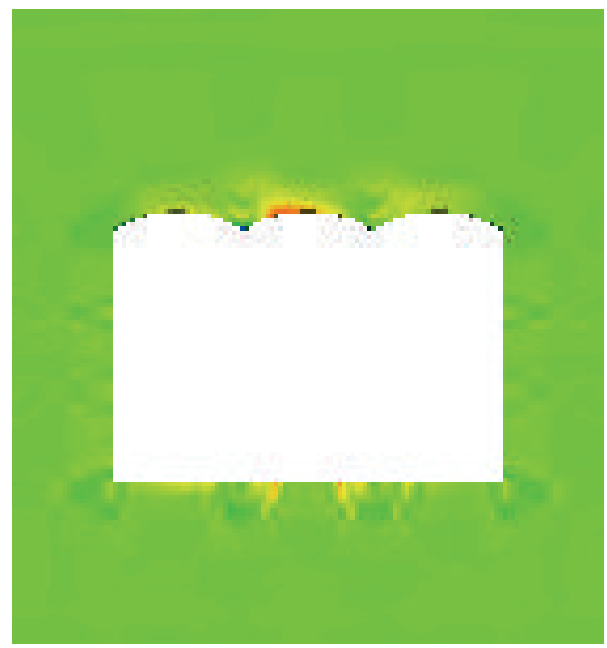

(a) Minimum principle stress

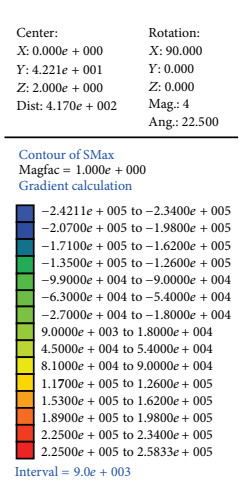

Itasca Consulting Group, Inc.
Minneapolis,, NN USA

FIGURE 12: Surrounding rock principle stress contour map of PBA.

at $3.30 \mathrm{MPa}$; they all cause the surrounding rock generating tension stress area and tension stress serious concentration appearing near the vault of the middle cavity; the tension stress of the side cavity method is greatest, $0.58 \mathrm{MPa}$; then the PBA follows, which is $0.26 \mathrm{MPa}$; the middle cavity method provides the lowest stress, $0.16 \mathrm{MPa}$.

\subsection{Force Characteristic Analysis of Support Structure}

5.3.1. Anchor Rod Support. Figure 13 is the anchor rod axial force diagram of three excavation methods after the excavation is completed; in the diagram, black indicates the tension force of the anchor rod, and red indicates the pressure force of the anchor rod. In the three excavation methods, the position with the maximum force of the anchor rod is the vault, wherein pressure of the anchor appears at both sides of the vault of every cavity in the side cavity method and the middle cavity method, and the maximum axial force of the construction anchor rods of the two methods is, respectively, $25190 \mathrm{~N}$ and $27640 \mathrm{~N}$; and for the PBA construction the anchor rods at the top of the cavity are all pressed, and the maximum tension load of the anchor rod is $26450 \mathrm{~N}$.

Seen from the axial force characteristic of the anchor rod, the anchor rod bears the most sufficient force through middle cavity method for construction, and the side cavity method follows.

5.3.2. The Second Lining. Figures 14,15 , and 16 show, respectively, distribution diagram of minimum and maximum principle stress of secondary support. 
TABLE 5: Comparative table of phase-excavation surrounding rock stress in different construction methods.

\begin{tabular}{lccc}
\hline Construction method & Maximum pressure stress (MPa) & Maximum tension stress (MPa) & Ratio \\
\hline Side cavity method & 2.04 & 0.58 & 3.52 \\
Middle cavity method & 2.04 & 0.16 & 12.75 \\
PBA method & 3.30 & 0.26 & 12.69 \\
\hline
\end{tabular}

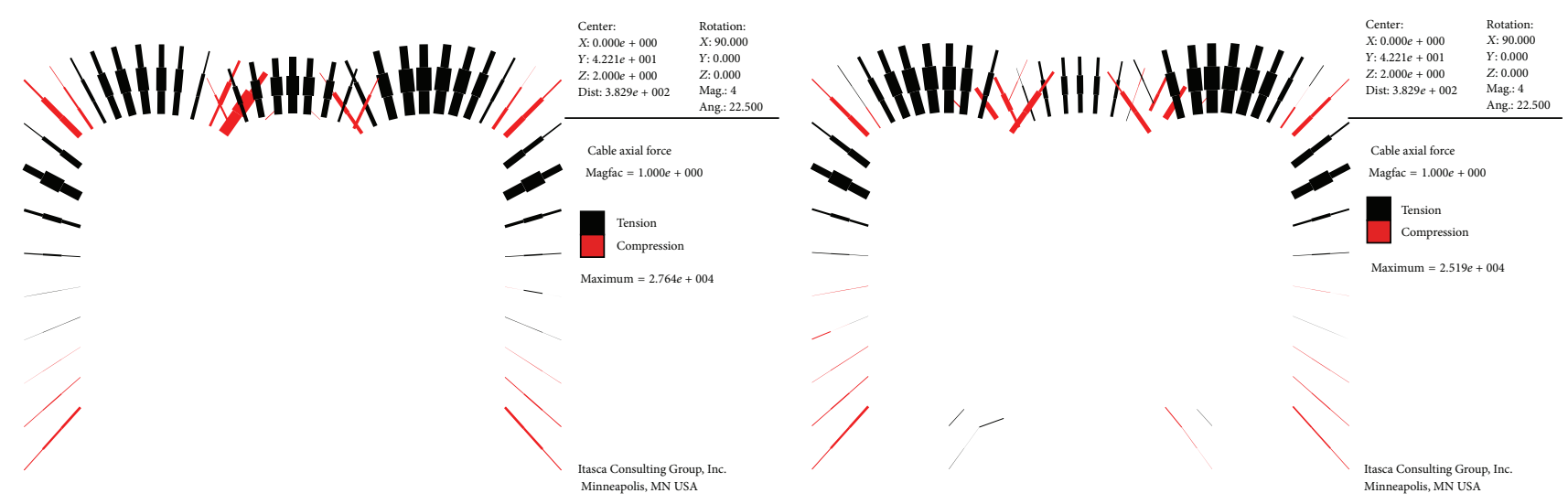

(a) Side cavity method

(b) Middle cavity method

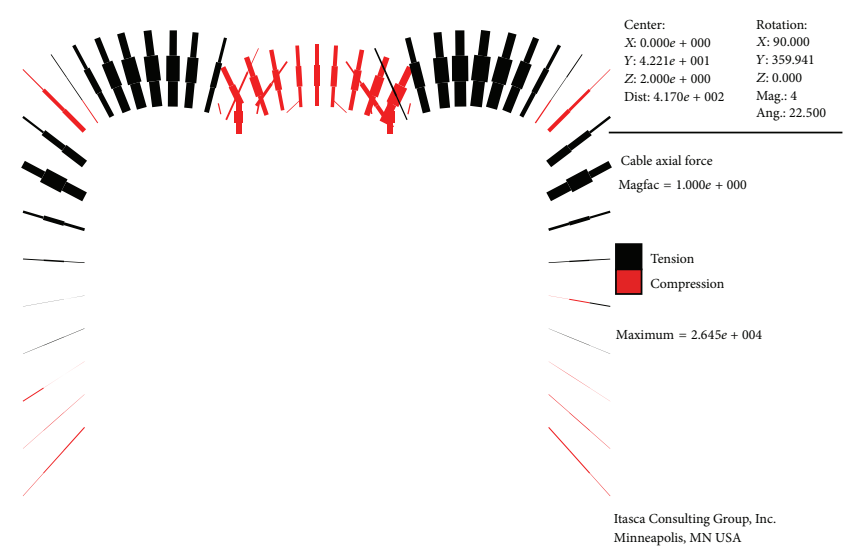

(c) PBA completed

FIGURE 13: Anchor rod axial force after the excavation is completed.

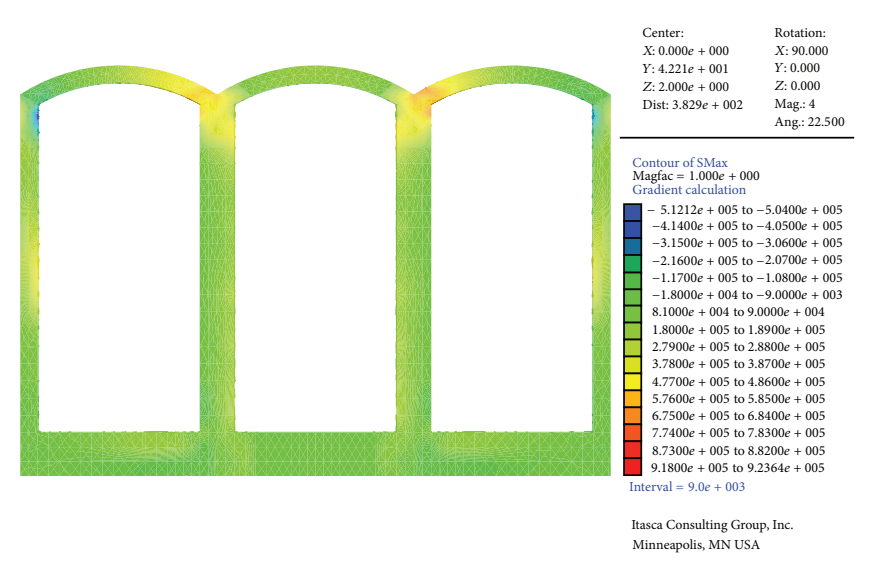

(a) Minimum principle stress

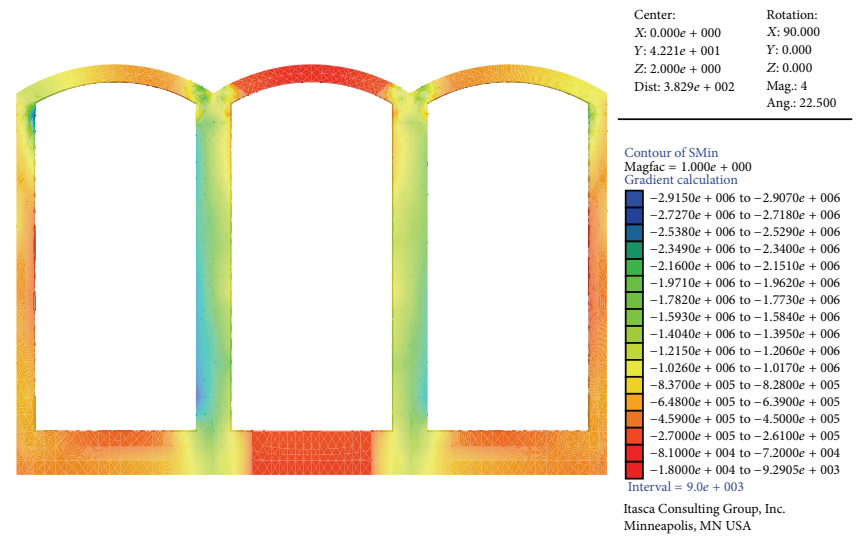

(b) Maximum principle stress

FIGURE 14: Second lining principle stress contour of side cavity method. 


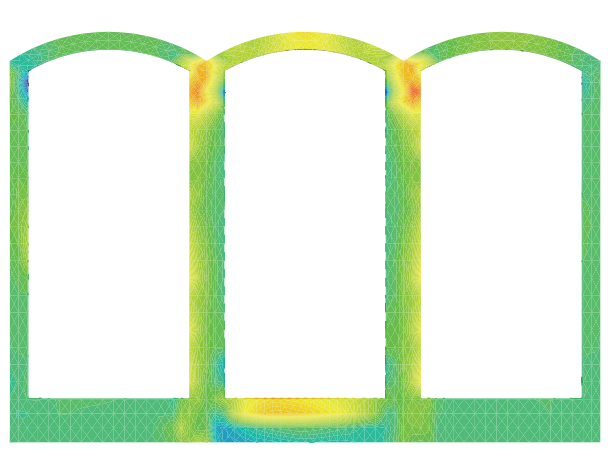

(a) Minimum principle stress

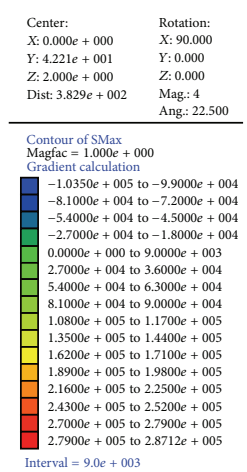

Itasca Consulting Group, Inc
Minneapolis, MN USA

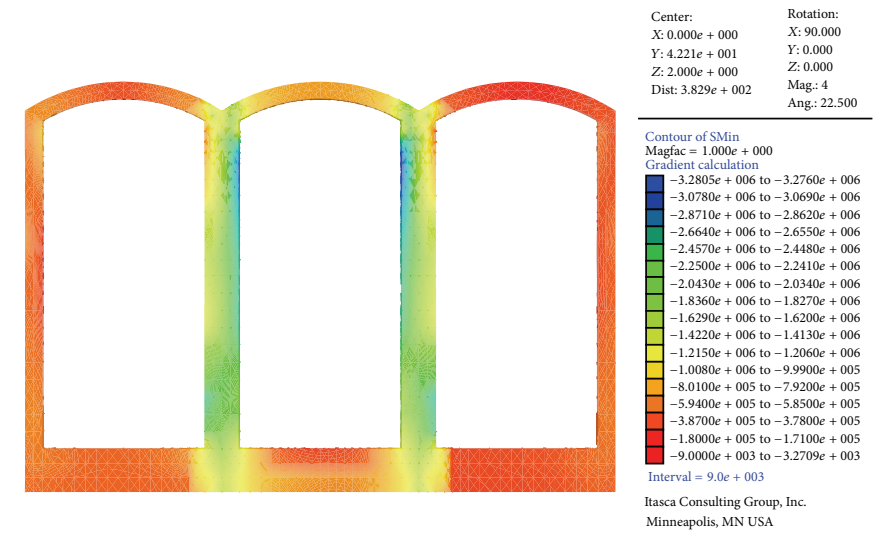

(b) Maximum principle stress

FIGURE 15: Second lining principle stress contour of middle cavity method.

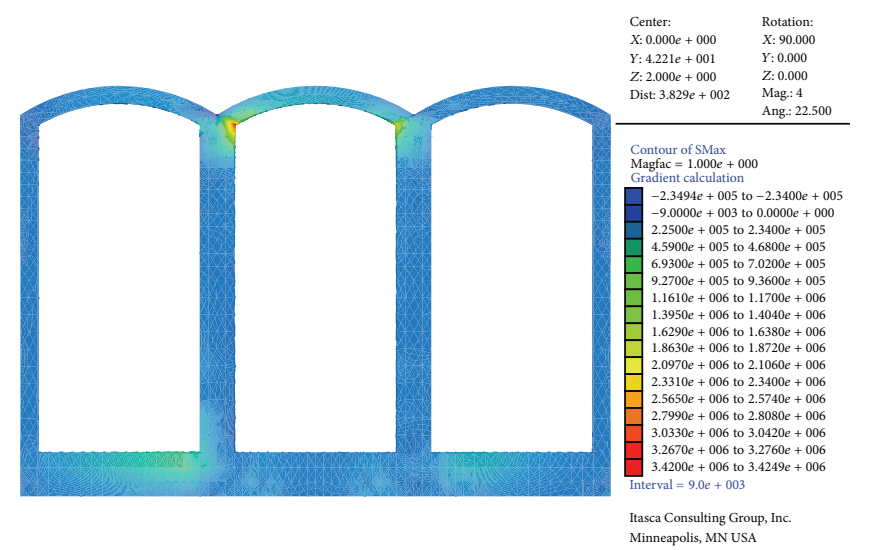

(a) Minimum principle stress
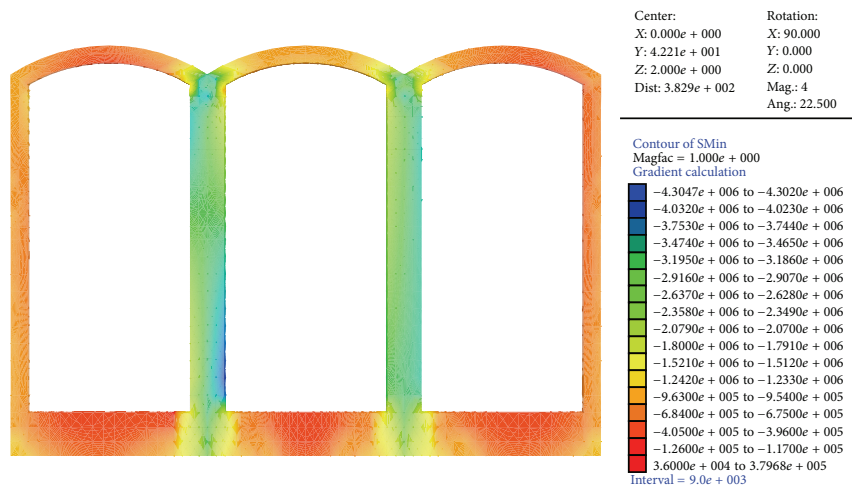

Itasca Consulting Group, Inc
Minneapolis, MN USA

(b) Maximum principle stress

FIgURE 16: The second lining principle stress contour map of PBA.

Seen from the figure, the main distribution rule of the maximum principle stress of the secondary support is basically the same, the maximum value always appears at two sides of the middle cavity and the joint part of two side cavities; the maximum value of the middle cavity method is $0.287 \mathrm{MPa}$ and that of PBA is $0.34 \mathrm{MPa}$; the minimum principle stress concentration mainly appears at the stand column and support position of the beam; the maximum value of side cavity construction is $-2.92 \mathrm{MPa}$, while that of middle cavity construction is $-3.28 \mathrm{MPa}$ and that of PBA construction is $-4.30 \mathrm{MPa}$. Concrete is mainly a pressure part; the appearance of tension stress might lead to tension failure in the secondary support concrete. The construction by middle cavity method provides relatively lighter secondary support force, without heavy tension stress, so as to be the optical support scheme.

5.4. Distribution Feature Analysis of Plastic Zone around the Cavity. Even the creep property of the surrounding rock is considered in the construction, and the calculated maximum value of displacement and stress is not great; the underground cavities may also come up with surrounding rock falling, collapse, and other unstable phenomenon. Therefore, the surrounding rock plastic zone distribution during the construction of the cavities will be considered as well.

After the construction is completed, the plastic zone distribution can be seen in Figures 17(a), 17(b), and 17(c). It can be seen from the figure that the surrounding rock plastic yielding area of PBA is the largest, and the construction of middle cavity method causes smaller plastic yielding area to the surrounding rock of the cavity.

Therefore, after comprehensive comparison and analysis of surrounding rock creep property, surrounding rock stress field distribution features, support structure force characteristics, and construction caused by surrounding rock plastic zone expansion condition, this paper shows the point that in the three construction schemes, the middle cavity method is the optimum scheme, and the PBA follows. 


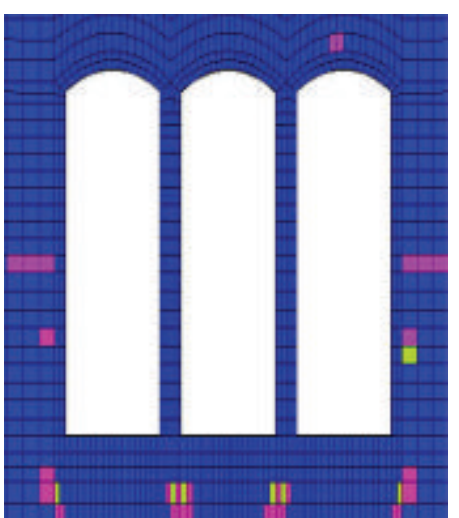

Block state

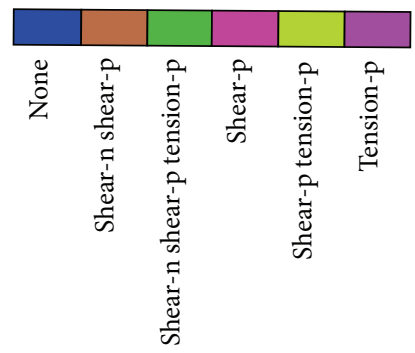

(a) Side cavity method

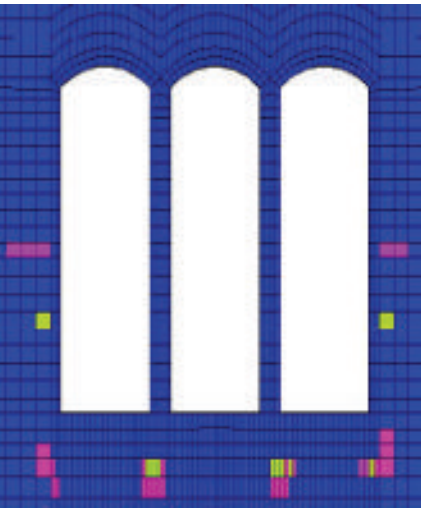

Block state

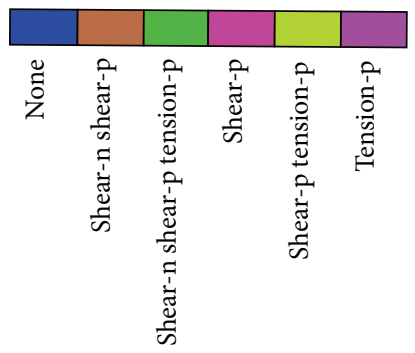

(b) Middle cavity method

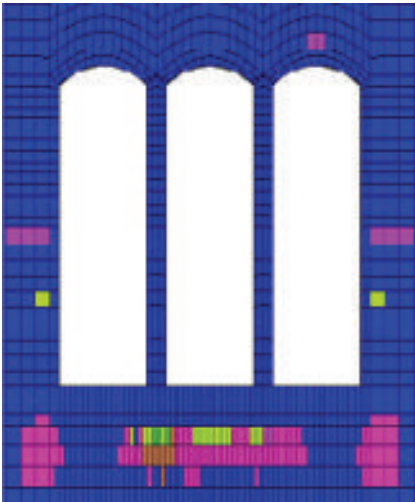

Block state

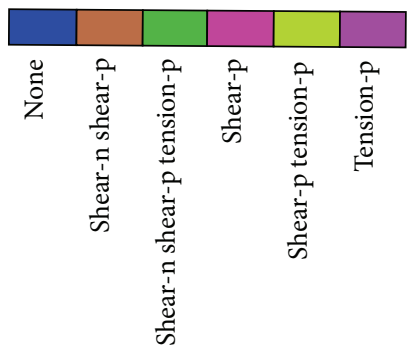

(c) PBA

FIGURE 17: Surrounding rock plastic zone expansion.

\section{Conclusions}

When the nonlinear viscoelastic-plastic creep model is adopted, the construction development scheme for longspan three-connected-arch underground hydraulic cavity somewhere in Shenzhen is optimized, and the following conclusions are obtained.

(1) The nonlinear viscoelastic-plastic creep model can be well applied to the construction optimization analysis for large-scale underground cavities.

(2) From the point of surrounding rock's creep displacement, it is obtained that the PBA is the optimal scheme, and the middle cavity method follows.

(3) Seen from the point of surrounding rock's stress, the force characteristic of support structure, the expansion of surrounding rock's plastic zone, and difficulty level of construction, the middle cavity method is the optimal scheme.

(4) From the comparison and selection of numerical simulated construction of the three construction schemes, the cavity vault displacement is $16.04 \mathrm{~mm}$ by adopting the middle cavity method for construction, this method causes smaller stress redistribution to the cavity surrounding rock, the maximum tension stress in the surrounding rock is only $0.16 \mathrm{MPa}$, and even the plastic zone expansion is smaller than the other two schemes, so it is the optimal construction scheme.

\section{Conflict of Interests}

The authors declare that there is no conflict of interests regarding the publication of this paper.

\section{Acknowledgments}

This work was funded by the Natural Science Foundation of China (41302223), Chongqing Research Program of Basic Research and Frontier Technology (cstc2013jcyjA90004), Research Foundation of Chongqing University of Science \& Technology (CK2011B28, CK2014Z10, and CK2013B27), and Key Laboratory of Hydraulic \& Waterway Engineering of the Ministry of Education (SLK2013B03).

\section{References}

[1] J. H. Yang, W. B. Lu, Z. G. Zhao, P. Yan, and M. Chen, "Safety distance for secondary shotcrete subjected to blasting vibration in Jinping-II deep-buried tunnels," Tunnelling and Underground Space Technology, vol. 43, pp. 123-132, 2014.

[2] G. Y. Fu and G. W. Ma, "Extended key block analysis for support design of blocky rock mass," Tunnelling and Underground Space Technology, vol. 41, pp. 1-13, 2014.

[3] M. Pejić, "Design and optimisation of laser scanning for tunnels geometry inspection," Tunnelling and Underground Space Technology, vol. 37, pp. 199-206, 2013.

[4] H. H. Zhu, F. Huang, and Q. W. Xu, "Model test and numerical simulation for progressive failure of weak and fractured tunnel surrounding rock under different overburden depths," Chinese 
Journal of Rock Mechanics and Engineering, vol. 29, no. 6, pp. 1113-1122, 2010.

[5] H. Y. Pan, H. W. Zhang, S. G. Li, T. J. Zhang, and H. F. Lin, "Research on creep model and delay instability of coal-rock containing gas," Disaster Advances, vol. 6, no. S1, pp. 273-277, 2013.

[6] Z. G. Ma, Z. Huang, G. Peng, L. Zhang, and D. Ma, "Experimental study on creep behavior of saturated disaggregated sandstone," International Journal of Rock Mechanics \& Mining Sciences, vol. 66, pp. 76-83, 2014.

[7] W. Zhu, Y. Qi, Y. Guo, and W. Yang, "3D damage rheology analysis of deformation and fracture of surrounding rocks in Jinping I hydropower station underground powerhouse," Chinese Journal of Rock Mechanics and Engineering, vol. 31, no. 5, pp. 865-872, 2012.

[8] X. J. Dong, Z. K. Peng, W. M. Zhang, H. X. Hua, and G. Meng, "Research on spillover effects for vibration control of piezoelectric smart structures by ANSYS," Mathematical Problems in Engineering, vol. 2014, Article ID 870940, 8 pages, 2014.

[9] L. W. Zhang, Z. X. Lei, K. M. Liew, and J. L. Yu, "Static and dynamic of carbon nanotube reinforced functionally graded cylindrical panels," Composite Structures, vol. 111, pp. 205-212, 2014.

[10] R. J. Cheng, L. W. Zhang, and K. M. Liew, "Modeling of biological population problems using the element-free kp-Ritz method," Applied Mathematics and Computation, vol. 227, pp. 274-290, 2014.

[11] T. Kazerani and J. Zhao, "A microstructure-based model to characterize micromechanical parameters controlling compressive and tensile failure in crystallized rock," Rock Mechanics and Rock Engineering, vol. 47, no. 2, pp. 435-452, 2014.

[12] T. Kazerani, "Effect of micromechanical parameters of microstructure on compressive and tensile failure process of rock," International Journal of Rock Mechanics and Mining Sciences, vol. 64, pp. 44-55, 2013.

[13] Itasca Consulting Group, FLAC 3D (Version 3.0) User's Manual, Itasca Consulting Group, Minneapolis, Minn, USA, 1997.

[14] B. Y. Zhao, D. Y. Liu, Z. M. Zheng, and K. K. Xue, "Nonlinear visco-elastic plastic creep model of rocks based on the short time triaxial creep test," Journal of Mining and Safety Engineering, vol. 28, no. 3, pp. 446-450, 2011.

[15] B. Y. Zhao, D. Y. Liu, Y. R. Zheng, and Q. Dong, "Secondary development and slope application discussion of the non-linear visco-elastic plastic creep model in Flac ${ }^{3 D}$ software," Disaster Advances, vol. 5, no. 4, pp. 1231-1236, 2012. 


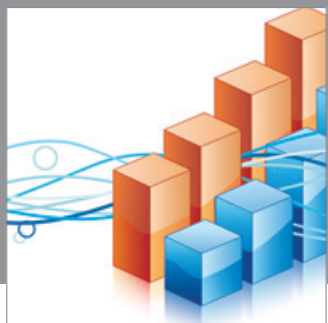

Advances in

Operations Research

mansans

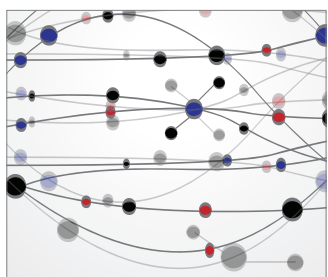

The Scientific World Journal
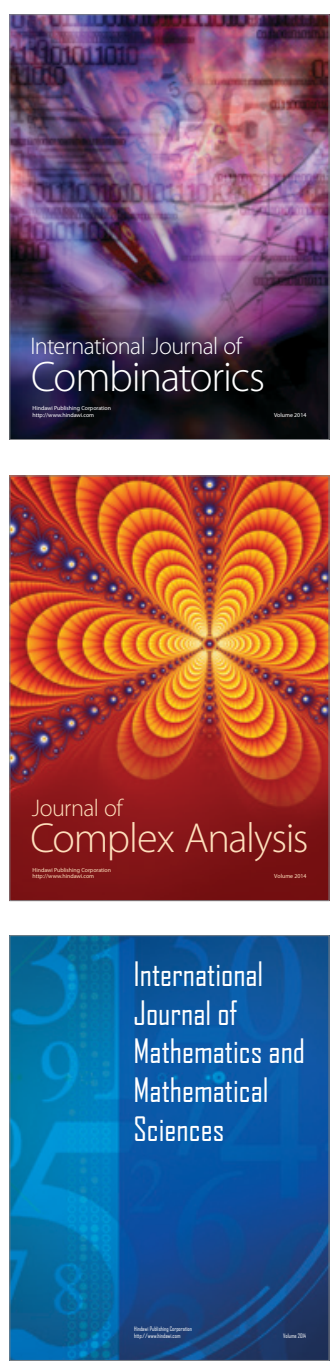
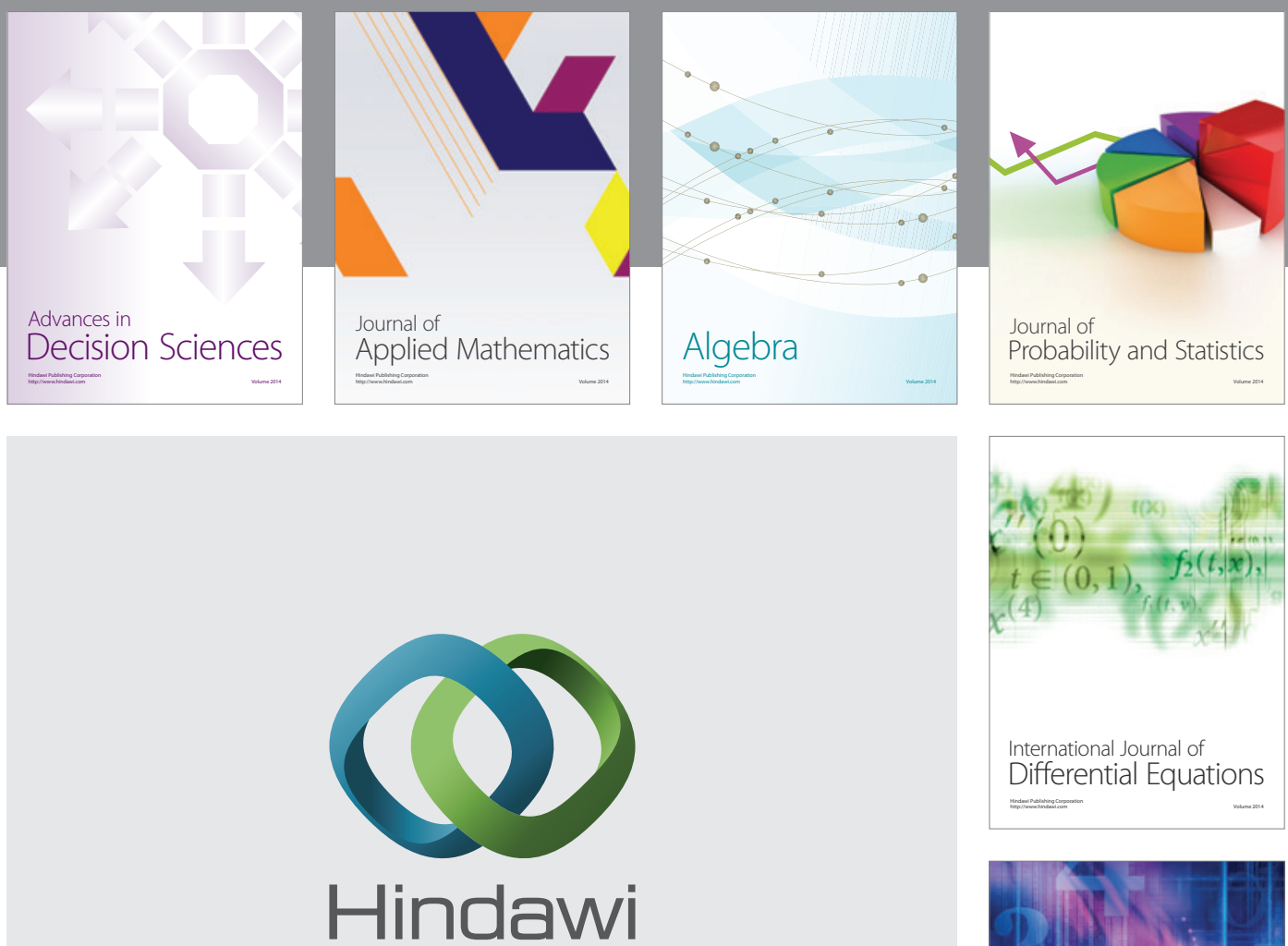

Submit your manuscripts at http://www.hindawi.com
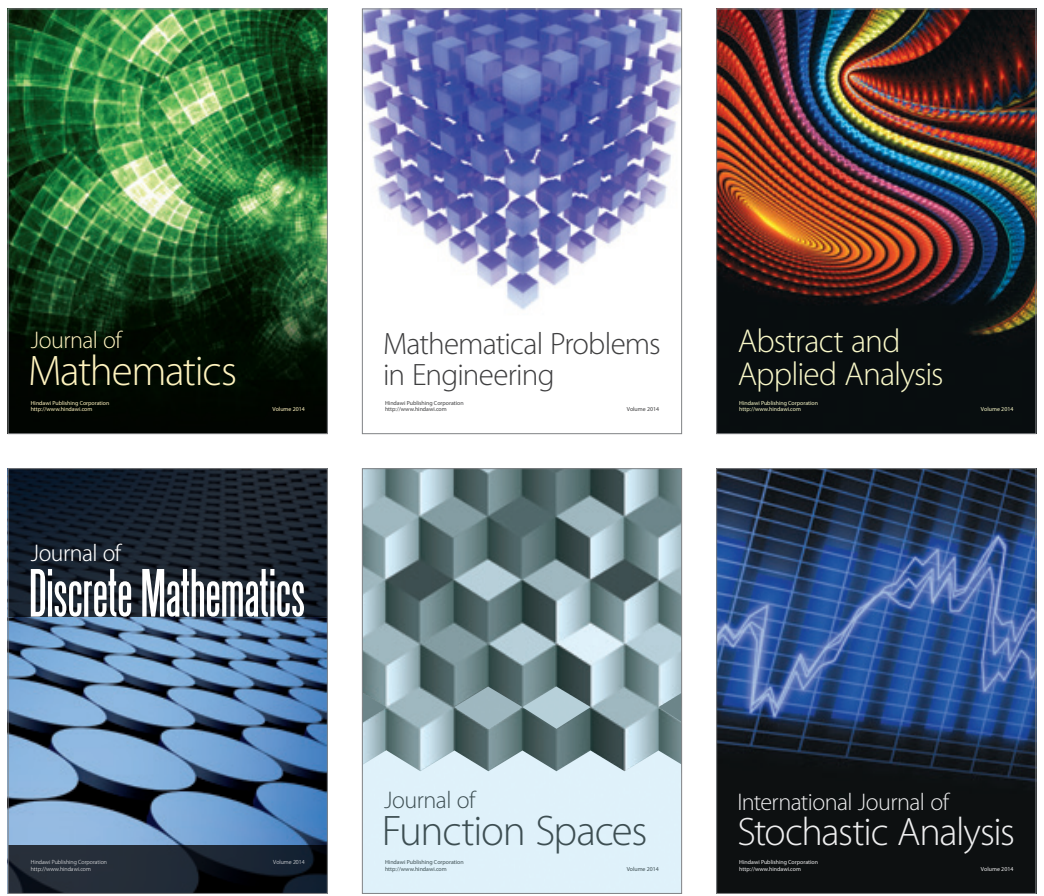

Journal of

Function Spaces

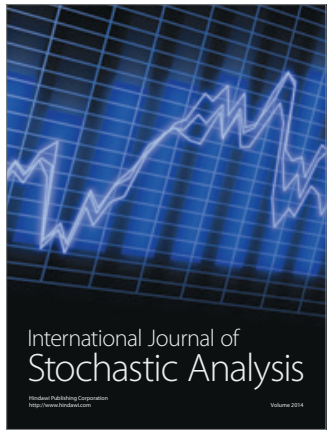

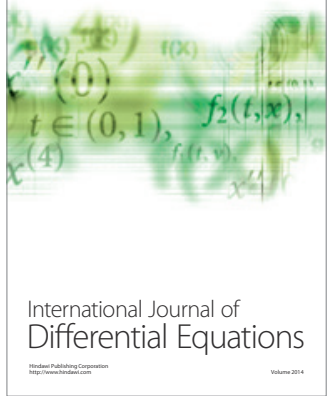
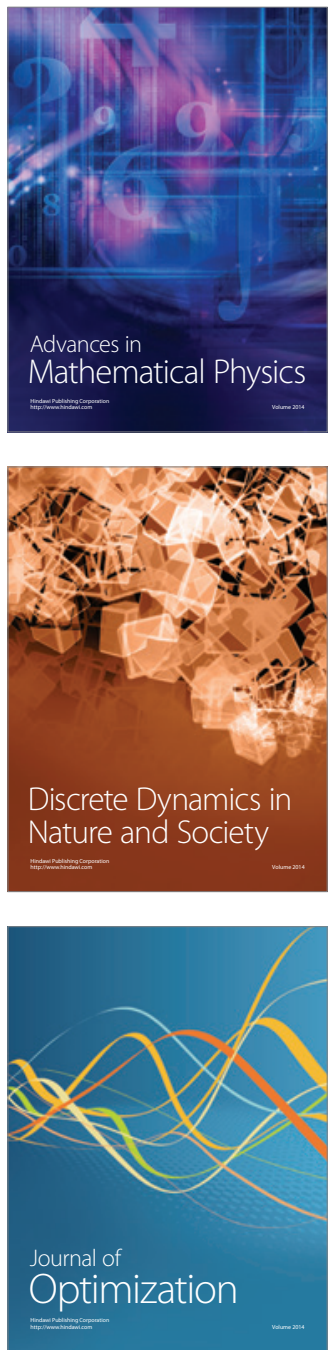